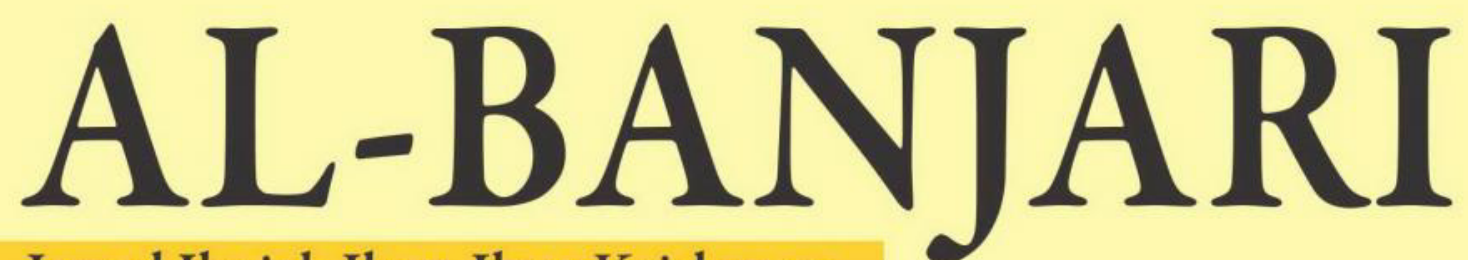

Jurnal Ilmiah Ilmu-Ilmu Keislaman

Takhrij Al-Hadits tentang Peralatan Makan Nabi SAW Hairul Hudaya

Peranan Ulama Banjar Abad Ke-20 dalam Tradisi Penulisan Hadis Arba'īn di Banjar dan Malaysia

Muhammad Hasan Said Iderus, Latifah Abdul Majid dan Ahamad Asmadi Sakat

Pendapat KH. Salim Ma'ruf tentang Jual Beli dalam Risalah Muamalah H. Fathurrahman Azhari dan Adi Hatim

\title{
Intervensi Anak dalam Perceraian
}

Firman Wahyudi

Peran BAZNAS Kota Banjarmasin dalam Pengembangan Usaha Mikro (Pendekatan Studi Kasus)

H.M. Ma'ruf Abdullah, Sri Anafarhanah dan Elida Mahriani

Pemikiran Reaktif tentang Hukum/Poligami dalam Al-Qur'an

(Pemikiran Quraish Shihab dalam Tafsir Al-Mishbah)

Norcahyono

ضو ابط الأحخ بالك خصة في قضايا اختلف فيها الفقهاء

Muhammad Yosef Niteh

\begin{tabular}{|c|c|c|c|c|c|}
\hline AL-BANJARI & Vol. 15 & $\begin{array}{c}\text { Halaman } \\
127-232\end{array}$ & No.2 & $\begin{array}{c}\text { Banjarmasin, } \\
\text { Juli-Desember 2016 }\end{array}$ & $\begin{array}{c}\text { ISSN: 1412-9507 } \\
\text { E-ISSN: 2527-6778 }\end{array}$ \\
\hline
\end{tabular}




\section{AL - BANJARI}

Jurnal Ilmiah Ilmu-Ilmu Keislaman

Vol. 15, No. 2, Juli-Desember 2016

\section{DAFTAR ISI}

Takbrij Al-Hadits tentang Peralatan Makan Nabi SAW

$127-146$

Hairul Hudaya

Peranan Ulama Banjar Abad Ke-20 dalam Tradisi Penulisan Hadis Arba'in

di Banjar dan Malaysia

$147-164$

Muhammad Hasan Said Iderus, Latifah Abdul Majid dan

Ahamad Asmadi Sakat

Pendapat KH. Salim Ma'ruf tentang Jual Beli dalam Risalah Muamalah 165-184 H. Fathurrahman Azhari dan Adi Hatim

Intervensi Anak dalam Perceraian

$185-194$

Firman Wahyudi

Peran Baznas Kota Banjarmasin dalam Pengembangan Usaha Mikro

(Pendekatan Studi Kasus)

$195-212$

H.M. Ma'ruf Abdullah, Sri Anafarhanah dan Elida Mahriani

Pemikiran Reaktif tentang Hukum Poligami dalam Al-Qur'an (Pemikiran

Quraish Shihab dalam Tafsir Al-Mishbah)

Norcahyono

ضو ابط الأخذ بالرخصة في قضايا اختلف فيها الفقهاء

Muhammad Yosef Niteh 


\title{
PERANAN ULAMA BANJAR ABAD KE-20 DALAM TRADISI PENULISAN HADIS $A R B A^{\prime} \bar{I} N$ DI BANJAR DAN MALAYSIA
}

\author{
Muhammad Hasan Said Iderus, Latifah Abdul Majid dan \\ Ahamad Asmadi Sakat \\ Jabatan al-Quran dan al-Sunnah, Fakulti Pengajian Islam \\ Universiti Kebangsaan Malaysia, 43600 UKM Bangi, Selangor, Malaysia \\ hasan.nabila98@gmail.com
}

\begin{abstract}
Banjar is famous for its great scholars and have an important role in the Islamic world. In this study, Banjarese scholars had passions and purposes to enhance, strengthen and develop the tradition of writing Hadith. The books of hadith they wrote is not only applicable in Islamic boarding school but also for public usage in this country as well as other countries. Banjarese scholars who was related to hadith Arba'in the 20th century were Kasyful Muhammad Anwar, Anang Sya'rani Arif, Muhammad Syukeri Unus, and Ahmad Fahmi Zamzam. This study attempts to explain the background of those scholars and their roles in the scientific tradition of Hadith in Banjar as an effort to introduce the Islamic scholars in Nusantara to Islamic world. This research is based on analysis of historical and biographical data obtained from the collection of documents and processed descriptively. The study found that the role of Banjarese scholars in the 20th century gave a new nuance to the study of hadith in Banjar and Malaysia.
\end{abstract}

Keywords: Banjarese scholars, hadis Arbaim, Islamic world.

\section{Pendahuluan}

Ulama memiliki peranan terhadap pembentukan dan pembangunan pemikiran umat Islam. ${ }^{1}$ Salah satu bentuk nyata usaha yang mereka lakukan adalah melalui penulisan hadis. Penulisan hadis yang dilakukan para ulama merupakan hal yang sangat penting untuk mempertahankan hadis-hadis yang diwariskan oleh Rasulullah SAW karena hadis Nabi SAW sangat diperlukan oleh kaum Muslimin. ${ }^{2}$ Hadis tidak hanya berlaku hanya satu masa atau satu generasi, ia diperlukan sepanjang masa pada setiap generasi. Hadis juga merupakan sumber ajaran Islam setelah al-Quran.

1 Ahdi Makmur, Peranan Ulama Dalam Masayarakat Banjar (Malaysia: Universiti Utara Malaysia, 2010) hlm. 185-186.

2 Umat Islam mengambil hukum-hukum yang diterima Rasulullah SAW sehingga hadis Nabi SAW berfungsi sebagai bayan. lihat Badri Khaeruman, Ulumul al-Hadis (Bandung: Pustaka Setia, 2010) hlm. 45-55. 
Jika melihat sejarah, maka dari masa ke semasa yang disaksikan dan dialami oleh umat dari masa ke masa, ialah persoalan kehidupan (keagamaan) terus berkembang dan bertambah. Untuk menghadapi kenyataan tersebut dengan kesedaran, kaum Muslimin harus merujuk kepada al-Quran dan hadis serta memahami kembali kandungankandungannya agar bisa diterapkan secara efektif. Justeru, dengan ditulisnya hadis kaum Muslim dapat menggunakan sebagai rujukan dengan mudah.

Peranan ulama terhadap tradisi penulisan hadis di Nusantara merupakan suatu kajian yang menarik perhatian sarjana Muslim mahupun bukan Muslim untuk diteliti dan dikaji. Hal ini disebabkan banyak hal yang diperolehi melalui kajian sejarah. Misalnya dengan kajian sejarah kita dapat melihat, membayangkan dan mengetahui lebih mendalam kemajuan atau kemunduran dari objek sejarah yang menjadi bahan kajian tersebut. Termasuk juga mengetahui keterkaitan antara mata rantai sejarah satu dengan sejarah yang lain. Justeru, kajian peranan ulama terhadap penulisan hadis sebagai bahan penelitian, namun dapat mampu memberikan sumbang untuk diambil pelajaran bagi kita di masa sekarang dan masa depan.

Kajian ini cuba untuk melihat peranan ulama Banjar terhadap tradisi penulisan hadis Arba'in adab 20 M. di tanah Banjar dan Malaysia. Mengapa kajian ini penting dan perlu dilakukan. kerana bagi Masyarakat Banjar dan Melayu, para ulama sangat di hormati dan memiliki kedudukan yang tinggi. Para ulama memainkan peranan penting terhadap dalam menyebarkan dan membangun sistem pendidikan di Banjar dan Melayu. Para ulama bergiat mengajarkan ilmu mereka kepada masyarakat sama ada di pengajian-pengajian surau mahupun di madrasah-madrasah. ${ }^{3}$

Banjar dan Malaysia merupakan satu rumpun dan telah melahirkan banyak ulama yang menekuni bidang kajian hadis sama ada menekuni hadis dirayah atau riwayah, mahupun sharh hadis. Ulama yang memberikan sharh seperti Abd al-Racuf bin Ali al-Jawi al-Fansuri (1615-1690 M) menulis bertajuk Sharh al-Latif 'Ala Arba'in Hadis li al-Imam an-Nawawi dan al-Mawa'iz al-Badi'ah. Terdapat pula kitab Hidayah al-Habib fi al-Targhib wa al-Tarbib yang kemudian terkenal dengan nama al-Fawaid al-Babiyyah fi al-Ahadis al-Nabawiyyah. ${ }^{4}$

Selanjutnya Nuruddin Ar-Raniri (w. 1658 M) ini menjadi kitab pertama yang ditulis dengan bahasa Melayu. Kitab ini mengandung sekitar 823 hadis yang terkait dengan Targhib dan Tarhib. Nawawi al-Bantani al-Jawi (w. 1230 H/1813 M-1314 H/1897 M) yang menuliskan kitab sharh, Tanqih al-Qaul Sharh Kitab Lubabul Hadis karya Imam al-Suyuthi dan Nashaihul 'Ibad. Haji Wan Ali bin Haji Abdul Rahman al-Kelantani yang lebih dikenal Tok Wan Ali Kutan (1837-1912 M) di Kelantan yang melakukan pengajaran mengenai al-Qur'an dan hadis. Begitu juga setelahnya muncul nama Abu Abdullah Sayyid Hassan bin Nur Hasan (1875-1944 M) atau lebih dikenal

\footnotetext{
3 Semenangjung tanah Melayu ulama telah memainkan peranan cukup pentig sejak abad ke 17 M.lihat Shukri Ahmad. Pengaruh Pemikiran Ulama Di Semenanjung Malaysia Akhir Abad Ke-20. (Kedah: UUM Press. 2014) hlm. 3-16. Kedah merupakan salah satu tempat ulama Banjar mendapatkan tempat dan memberikan peranan mereka dalam pendidikan. lihat Suhanim Abdullah. Pemikiran Tokoh Ulama Banjar Kedah (Batu Pahat: Awijaya Enterprise. 2014) hlm. 51.

${ }^{4}$ Mazlan Ibrahim, Haziah Hussain, dan Latifah Abdul Majid. Warisan Hadisth Ulama Nusantara (Bangi: Universiti Kebangsaan Malaysia, 2012) hlm. 11-12.
} 
sebagai Tok Khurasan yang merupakan salah seorang ulama hadis terkemuka di Nusantara. Jika dilihat maka ulama memiliki peranan terhadap penulisan hadis di Nusantara.

Berdasarkan latar belakang yang telah diuraikan di atas, maka dipandang perlu untuk membahas peranan ulama Banjar abad 20 terhadap penulisan hadis Arba'in di Banjar dan Malaysia. Siapakah tokoh ulama banjar yang berpengaruh terhadap perkembangan penulisan hadis abad ke 20 M.? Bagaimana bentuk penulisan hadis yang dilakukan ulama banjar di abad 20 M.?

\section{Metode Kajian}

Metode kajian merujuk kepada kaedah yang sesuai untuk menjalankan penyelidikan dan menentukan tatacara efektif bagi menjawab permasalahan kajian. Kaedah kualitatif telah di jalankan dalam menjalankan kajian ini. Kajian ini merupakan kajian dengan menggunakan metode analisis dokumen ${ }^{5}$ yang terdiri daripada tesis, buku, jurnal, artikel, dan bahan-bahan yang berkaitan. Adapun caranya Pertama: Pengumpulan data dijalankan melalui kajian kepustakaan yang meliputi segala bahan yang berkait dengan metode analisis sejarah digunakan bagi mendapatkan data-data yang berkaitan dengan riwayat hidup para ulama Banjar abad 20 M iaitu: Muhammad Kasyful Anwar al-Banjari, Anang Sya'rani Arif, Muhamad Syukeri Unus, dan Ahmad Fahmi Zamzam berserta karya-karya mereka dalam bidang hadis. Kajian ini juga menggunakan metode sejarah iaitu untuk melihat sejarah penulisan hadis di Banjar abad 20 M. Kedua: Bagi proses penganalisisan data pula, kaedah analisis deskriptif diaplikasikan. Kaedah ini diambil agar data-data yang dikumpulkan mengenai tajuk kajian dapat dibahagikan berdasarkan kajian supaya kelihatan tersusun. Oleh itu, kajian ini dapat dilakukan dengan lebih baik dan sistematik.

\section{Ulama Banjar dan Hadis Arba'in Abad 20 M.}

Peranan ulama Banjar banyak memberikan dampak terhadap dunia Islam terutama pada zaman mereka dan sesudahnya. Mereka memiliki saham yang besar terhadap perkembangan Islam dan penulisan hadis Arba' in di Nusantara. ${ }^{6}$ Agar kajian ini lebih terarah maka akan kajian ini lebih memfokuskan peranan mereka terhadap penulisan hadis Arba'in di Banjar dan Malaysia. Pertama akan dikenalkan biografi singkat ulama banjar yang menulis hadis $A r b a^{c}$ in di abad $20 \mathrm{M}$ serta peranan mereka dalam dunia penulisan hadis Arbain.

\section{Biografi Singkat Muhammad Kasyful Anwar}

Nama beliau adalah Muhammad Kasyful Anwar dilahirkan di kampung Melayu, Martapura, Kalimantan Selatan Indonesia hari bulan Isnin 4 Rajab 1304 H. bertepatan 29 Mach 1887 M. Beliau merupakan anak kepada pasangan Haji Ismail bin Haji

\footnotetext{
5 Ahmad Sunawari Long, Metodologo Penyelidikan Pengajian Islam (Bangi: Penerbit Universiti Kebangsaan Malaysia, 2015) hlm. 65-68.

6 Rahmadi, Husaini Abbas. Islam Banjar Genelogi Dan Refrensi Intelektual Dalam Lintasan Sejarah (Banjarmasin: Antasari Press, 2010) hlm. 69-95. lihat juga Tim Pustaka Basma. Tiga Permata Ulama Dari Banjar (Malang: Pustaka Basma, 2014) hlm. 21-23.
} 
Muhammad Arshad dan Hajjah Siti Maryam binti Haji Abdurrahim. Sejak kecil beliau mendapatkan pendidikan Agama dari ibu bapa dan ulama-ulama tempatan. Usia 26 tahun tepatnya di bulan Syawal beliau menikah dengan Siti Halimah binti Ja'far dan di karunia 6 anak (4 laki-laki, (2 orang perempuan) iaitu: Muhammad Abdul Murad, Muhammad Arshad, Siti Maryam, Mardiyah, Muhammad dan Ahmad Salih. ${ }^{7}$

Pada tahun 1313 H. beliau berangkat ke Makah bersama Ibu bapa serta datu dan neneknya. Di sana beliau sangat bersungguh-sungguh dan rajin mempelajari agama sehingga menjadikan beliau ulama yang pandai. Kasyful Anwar ialah seorang berazam kuat untuk belajar bahasa Arab, selain belajar di rumah dengan ayahnya sendiri, beliau juga belajar kepada Muhammad Amin bin Mahmud bin Asiah binti Muhammad Arsyad al-Banjari, merupakan ulama dari Pasayangan, Martapura, Kalimantan Selatan, yang telah lama bermastautin di Makah.

Guru beliau selama di Makah ialah:

- Sheikh 'Umar Hamdān al-Mahrūs, yang bergelar Muḥaddith al-Haramayn

- Sheikh Muḥammad Yahyā al-Yamānī

- Sheikh Sa’̄id bin Muḥammad al-Yamānī

- Sheikh 'Umar Ba Junayd, seorang Mufti Shafi'iyyah

- Sheikh Muhammad Ṣāīin bin Muhammad Ba Faọll

- Sheikh Muhammad Ahyād al-Bughurī

- Sheikh Sayyid Muhammad Amīn al-Quṭbī

- Sheikh Sayyid Aḥmad bin Hasan al-'Ațtās, penulis kitab Tadhkīr al-Nās

- Sheikh Sayyid Aḥmad bin Sheikh Sayyid Abū Bakr bin Sheikh Sayyid al-'Ārif billāh Sayyid Muḥammad Shațā', putera penulis kitab I'ānah al-Tāalibīn.

- Sheikh Muhammad 'Alī bin Huseyn al-Malikī, bergelar Sibawaihi karena kealiman nya. ${ }^{8}$

Setelah bermukim selama 17 tahun untuk belajar di Makkah beliau kembali ke kampung halaman. Kemudian setelah menerapkan ilmu selama 20 tahun di tanah air pada tahun $1350 \mathrm{H} / 1930 \mathrm{M}$, ia kembali ke Tanah Suci bersama isteri dan kedua anaknya serta membawa dua orang kemanakan nya iaitu Anang Sya'rani Arif dan Muhammad Syarwani Abdan (keduanya kelak menjadi ulama besar). Keberangkatan beliau selain untuk memperdalam ilmu agama, beliau juga mengajar di Masjid al-Haram, Makah. Beliau hanya bermastautin di sana selama 3 tahun. Pada tahun tanggal 17 Safar 1353 $\mathrm{H}$, beliau kembali ke tanah air untuk mengabdi di kampung halaman yakni Kampung Melayu, Martapura. Sedangkan kemanakan beliau meneruskan pendidikannya di kota suci tersebut.

Sekembalinya dari Tanah Suci Makkah, beliau diminta oleh masyarakat membuka pengajian di rumahnya sendiri. Pada tahun $1922 \mathrm{M}$, beliau menjadi pemimpin Madrasah Darussalam periode ketiga. Masa kepemimpinan beliau banyak perubahan dan kemajuan yang beliau gagas selama memimpin. Pembaharuan tersebut menuntutnya

7 Dahlan Bayani. Ulama Banjar Dan Karya-Karyanya (Banjarmasin: Antasari Press, 2009) hlm. 44

8 Munawwar bin Ghazali. t.th. Nur Al-Abșār Fï Ziker Nubzah Min Manaqib Al-Shaikh Muhammad Kasyful Anwar (Martapura: Putra Sahara Ofset. t,th) hlm. 23. 
untuk menghasilkan kitab dan buku pelajaran yang sesuai dengan kurikulum dan jenjang pendidikan yang dilaksanakan. Justeru, beliau menyusun sejumlah kitab dan buku pelajaran dalam pelbagai disiplin ilmu. Beberapa karya beliau hasilkan adalah:

- Hasbunā, merupakan kitab berisikan selawat Rasulullah saw.

- Risälah Fiqhiyyah, kitab yang di dalamnya membahas tentang dasar-dasar ilmu fikah yang berbahasa Arab.

- Risālah Tajwid al-Qurān, kitab ini berbahasa Melayu dengan menggunakan tulisan jawi serta di dalamnya menguraikan tentang dasar-dasar ilmu Tajwid.

- Risālah fi al-Tawhid, kitab yang menguraikan kepada dasar-dasar ilmu Tauhid, kitab ini ditulis dalam bahasa Arab.

- Risālah fì al-Sìrah Sayyid al-Mursalìn, kitab ini berbahasa Arab membahas permasalahan tentang sejarah ringkas kehidupan Nabi Muhammad SAW.

- Jadwal Falakiyah, kitab ini membahaskan tentang rumus-rumus ilmu falak berkaitan dengan penentuan jadwal waktu solat serta untuk memudahkan penentuan awal dan akhir tahun hijrah.

- Durūs al-Taṣrif, kitab ini memiliki empat juz, di dalamnya membahas ilmu tatabahasa Arab (sarf), beliau menguraikan menggunakan bahasa yang mudah difahami dalam perubahan bentuk-bentuk kata bahasa Arab. Kitab ini juga menjadi rujukan stander hampir di seluruh pondok pesantren salafiah di Banjar Kalimantan Selatan.

- al-Tabyīn al-Rawi Sarḥ 'Alā Arba'in al-Nawawì, kitab ini merupakan kitab terjemah dan penjelasan (sharh) bertulisan menggunakan jawi terhadap hadīth-ḥadīth dalam kitab Arba'in karya kepada Imam al-Nawawī. Kitab ini disebutkan bahawa menjadi kitab pertama sharh hadis Arba'in di Kalimantan Selatan Indonesia. ${ }^{9}$

Hasil karya beliau tersebut menunjukkan bawah beliau selain pakar dalam bidang hadis, beliau juga pakar dan menguasai pelbagai bidang agama seperti tentang tauhid, fiqah, tajwid, sejarah, bahasa, dan lain-lain. Sebahagian besar daripada kitab tersebut hingga sekarang masih diguna pakai oleh masyarakat Banjar, khususnya di Pondok Pesantren Darussalam, Martapura. Pada usianya yang ke-55 tahun, tepatnya pada malam Senin, 18 Syawal $1359 \mathrm{H} / 1940 \mathrm{M}$ beliau meninggal dunia. ${ }^{10}$

\section{Biografi Singkat Anang Sya'rani Arif}

Nama lengkap beliau adalah Anang Sya'rani bin Fathul Jannah Haji Muhammad Arif bin al-'Alim al-Fadhil Haji 'Abdullah Khatib bin al-'Alim al-'Allamah Khalifah Haji Hasanuddin bin Sheikh Muhammad Arshad al-Banjari. Beliau dilahirkan pada tahun 1914 M. di Kampung Melayu Ilir Martapura, Kalimantan Selatan, Indonesia.

\footnotetext{
9 Muhammad Hasan Said Iderus, dkk. al-Tabyin al-Rawi Sharh Arba'in al-Nawawi Kitab Sharh Hadis Pertama di Banjar "Kalimantan Selatan". (Malaysia Proseding Jejak. Warisan Ilmu Islam, 2016), hlm. 134-160.

${ }^{10}$ Muhammad Hasan. Peta Perkembangan Kajian Hadis Al-Arbacin Di Kalimantan Selatan. (Banjarmasin: Antasari Press. 2014) hlm. 39
} 
Pendidikan beliau dimulai sejak kecil, dengan mengaji dan belakar kepada beberapa ulama yang ada di Martapura, seperti KH. Muhammad Kasyful Anwar yang merupakan padan kepada beliau. Pada tahun 1350 H./1930 M., Anang Sya'rani bersama sepupunya, Muhammad Syarwani Abdan, berangkat ke Tanah Suci Makah untuk menunaikan ibadah haji, bersamaan menimba ilmu di sana. Di antara guru yang banyak memberikan pelajaran kepadanya ketika beliau berada di Kota Makah adalah:

- Al-'Ālim al-'Allāmah al-Sayyid Amīn al-Quṭ̂ī

- Al-'Ālim al-'Allāmah Shaikh 'Umar Hamdān

- Al-'Ālim al-'Allāmah Shaikh 'Alī bin 'Abdullāh al-Banjarī

- Al-'Ālim al-'Allāmah Shaikh Bakrī Shatạā

- Al-'Ālim al-'Allāmah Shaikh Muḥammad 'Alī bin Husayn al-Mālikī

- Al-'Ālim al-'Allāmah Shaikh Ahyād al-Bughurī

Sebab didikan yang mereka yang berikan dengan penuh keikhlasan, akhirnya beliau menjadi ulama masyhur dan ahli dalam bidang ilmu hadis dan tafsir. Justeru, beliau menyandang gelar mubaddith iaitu seseorang yang pakar dan hafal dalam ribuan hadis (lengkap sanad dan matn). Kerana ketekunannya bersama sepupunya Muhammad Syarwani Abdan, maka keduanya menjadi terkenal di tanah suci dengan gelaran "Dua Mutiara dari Banjar". Selama 22 tahun belajar di Tanah Suci Makah menjadikan beliau selai belajar juga pengajar di Masjid al-Haram. maka pada tahun 1952 M. beliau kembali pulang ke tanah air.

Pada tahun 1959 M., beliau dipercayai oleh KH. Abdul Qodir Hasan, pimpinan pondok pesantren Darussalam Martapura untuk menggantikannya sebagai pimpinan hingga tahun 1969 M. Pada masa kepemimpinan beliau, pondok diberi nama "Madrasah Islam Darussalam". Usaha beliau berbuah manis kerana beliau menetapkan tingkatan madrasah dengan tingkatan; Ibtidaiyah 2 tahun, Thanawiyah 2 tahun, Aliyah 3 tahun, serta menambah "Isti'dād al-Mu'allimīn" dan Fakultas "Syariah Darussalam" sebagai tingkatan perguruan tinggi. Beliau juga membentuk Majlis Shuyūkh, yakni perkumpulan para ulama untuk bermusyawarah dan memutuskan perkara-perkara agama, di samping itu juga mengadakan pengajian khusus kepada guru-guru di rumah beliau.

Sebelum wafat, beliau berwasiat dan menunjuk KH. Muhammad Salim Macruf untuk menggantikan beliau sebagai Pimpinan Madrasah Darussalam. Akhirnya, pada hari bulan Selasa, 14 Jumadil Ula 1389 H. bertepatan 29 Jul 1969 M. beliau berpulang ke Rahmatullah membawa amal bakti yang tiada terhingga. Beliau dimakamkan di Kampung Melayu Tengah, Martapura Kalimantan Selatan.

Karya-karya beliau dalam hadis, iaitu: Tanwir al-Tulläb fi Mushțalah al-Hadith, Kitab ini merupakan kitab yang membahas ilmu hadis. Hidāyah al-Zamān min Ahädìth Äkbir al-Zamān. Kitab ini merupakan kitab yang memuat hadis-hadis akhir zaman. ${ }^{11}$

${ }^{11}$ Kitab ini merupakan kitab yang sering di guna pakai di kalangan Pesantren Darussalam Marttapura. Anang Sya ${ }^{c}$ rani Arif. Hidāyah Al-Zamān Min Ahädìth Äkbir Al-Zamān. hlm. 1. Biografi beliau slila lihat Muhammad Hasan. Peta Perkembangan Kajian Hadis Al-Arbacin Di Kalimantan Selatan. (Banjarmasin: IAIN Antasari 2014) hlm. 40-44. lihat juga Saifuddin; Dzikri Nirwana, dan Bashori. Peta Kajian Hadis Ulama Banjar (Banjarmasin IAIN Antasari Press, 2014) hlm. 125-129. 


\section{Biografi Singkat Muhammad Syukeri Unus ${ }^{12}$}

Nama beliau Muhammad Syukeri bin Unus dilahirkan pada hari bulan Isnin 5 Oktober 1948 M. bertepatan 1 Zulhijah 1367 H., di desa Harus, Sungai Malang, Amuntai Tengah Hulu Sungai Utara. Ayah beliau bernama Unus bin Ali bin Abd Rasyid, dan ibunya bernama Hajjah Mascinta bin Sa'ad bin Abd Rasyid. Beliau dilahirkan daripada keluarga yang taat beragama. Kewafatan ayahnya membuat beliau pada tahun 1963 M., beliau memutuskan untuk berhijrah ke kota Martapura untuk mendalami ilmu agama di Pondok Pesantren Darussalam.

Masa muda beliau dikenal sebagai pemuda cerdas. Hal ini dibuktikan beliau dengan selalu menduduki peringkat pertama di kelas sejak SD, SMP, hingga beliau meneruskan sekolah di Pondok Pesantren Darussalam. Ketika masih tinggal di Amuntai, sekitar tahun 1958-1963 M., beliau selalu mengikuti pengajian-pengajian beberapa ulama terkenal, di antaranya seperti:

- KH. Abdul Hamid (Guru Tuha Haji Tarus)

- KH. Muhammad Suberi

- KH. Abd. Muthalib

- KH. Mansur

- KH. Asy'ari

- KH. Hasan

- KH. Abdul Wahab Sya'rani

- KH. Muhammad Imberan (Bung Tomo).

Pada hari bulan Senin, 10 Augustus 1978 M., beliau menikahi Hajjah Ramlah, sepupu daripada Tuan Guru KH. Muhammad Zaini Ghani (Guru Sekumpul), putri dari pasangan Haji Asy'ari dan Hajjah. Siti Zaleha. Dari pernikahan ini, beliau di karunia tiga anak, iaitu: M. Noor, Habibah, Laila Badriyyah. Beliau menghidupi keluarganya dari hasil sewa asrama milik saudaranya, dan penjualan kitab-kitab karangan beliau yang banyak dijadikan panduan berbagai pesantren di Kalimantan Selatan. Sampai sekarang, beliau bermukim dan mengajar serta membuka pengajian di Martapura. Beliau juga kerap mengadakan pengajian di kampung kelahiran beliau.

Muhammad Syukeri Unus adalah salah seorang ulama Banjar yang selalu berkarya dan produktif menulis. Di antara karya beliau yang dapat disebutkan seperti:

- Kajian Manakib seperti Manāqib Sayyidatinā Khadīa, Nubdzah Karāmät Siti Khadījah, Tarjamah Imam al-Syäf'i, Nubdhah Manāqib Shaikh 'Abd al-Qädir alJaylāni, Manāqì Imām Rabbāni Sayyid Abmad al-Badawì, Manāqib Imām Rabbānì Sayyid Abmad Rifä̀̄, Manāqib Imām Abu al-Hasan al-Syädhilì, Manāqib Abmad bin Idrìs al-Idrìsī, Manāqib Imām Rabbānì Shaikh Ibrāhìm al-Dasūqī, Tarjamah Shaikh Muhammad bin Sa'ìd al-Busyayrī, Tarjamah Shaikh Muhammad bin Sulaimān al-Jazǖì

- Kajian tata bahasa Arab seperti Is'äf al-Ṭälibin, Is äf al-Murid, Dalìl al-Wädihah, Tàìq Isyārah al-Maqäl, Tawdhìh al-Masālik

\footnotetext{
${ }^{12}$ Dzikri Nirwana, dan Bashori. Peta Kajian Hadis Ulama Banjar (Banjarmasin IAIN Antasari Press, 2014) hlm. 129-134.
} 
- Kajian Fiqah seperti Is'äf al-Hayd, Asrär al-Sawm (Rahasia Puasa), Risalah Rahasia Haji dan Umrah.

- Kajian Mantiq: Miftäh'Ilm

- Kajian Tauhid: Dalil al-Murid

- Kajian Akhlak: Irsyäd al-Awläd.

- Kajian Hadis seperti Dalïlal-Tälibin fì Ma'rifah Asmä' al-Hadìth, Hadìth al-Arba'in fi al-'Im (40 Hadis Kelebihan Ilmu dan Ulama). ${ }^{13}$

\section{Biografi Singkat Ahmad Fahmi Zamzam}

Ahmad Fahmi bin Zamzam di lebih dikenali dengan penanya dengan nama Abu Ali al-Banjari al-Nadwi al-Maliki. Beliau dilahirkan di Amuntai, Hulu Sungai Utara, Kalimantan Selatan, pada tanggal 9 June 1959 M. Pendidikan awal beliau didapat di kampungnya sendiri. Seterusnya pada tahun 1973-1978 M., beliau melanjutkan pelajarannya di Pondok Pesantren Darussalam Martapura, Kalimantan Selatan.

Pada tahun 1979 M., Ahmad Fahmi Zamzam melanjutkan pelajarannya di Yayasan Pesantren Islam yang lebih dikenal dengan nama YAPI Bangil, Jawa Timur. Pada tahun 1980 M., kemudian beliau melanjutkan pendidikannya di Nadwah al-'Ulamā, Luknaw, India. Pada masa itu beliau belajar di bawah asuhan tokoh ulama sangat terkemuka di dunia Islam iaitu Sayyid Abū al-Hasan 'Alī al-Hasanī al-Nadwī (w. 1420 H./1999 M.), di sana beliau belajar hingga memperoleh ijazah pertama (BA.) pada tahun 1983 M. Pada tahun 1984 M., beliau berkunjung ke negeri Kedah, Malaysia, dan tinggal di Ma'had Tarbiyah Islamiyah Derang, Pokok Sena, Kedah. Inilah merupakan awal daripada mula pengabdian beliau di Malaysia.

Kemudian pada tahun 1985 M., beliau kembali ke India untuk menyelesaikan pelajarannya pada tingkat Sarjana (Master) Beliau di sana belajar dalam bidang kajian Dakwah dan Sastra Arab dan diselesaikannya pada tahun 1987 M. Pada tahun 1988 M., beliau menyempatkan untuk berguru di kota Makkah, kepada Shaikh Muhammad Yāsīn al-Fadanī (w. 1410 H./1990 M.) di sana beliau memperoleh al-Ijāzah al-'Āmmah dalam ilmu hadis dari gurunya itu. Selain itu, beliau juga sempat berguru kepada Sayyid Muhammad bin 'Alwī al-Mālikī al-Hasanī (w. 1425 H./2004 M.), hingga dianugerahi oleh sang guru yang sangat mencintai dan dicintainya ini, dengan gelar "al-Mālikî" pada tahun $2002 \mathrm{M}$. atas pemahamannya yang mendalam terhadap persoalan-persoalan agama.

Ahmad Fahmi Zamzam telah berkhidmat lebih dari 20 tahun di Ma'had Tarbiyah Islamiyah Derang Kedah Malaysia, dalam usaha mendidik tunas-tunas muda dan memimpin mereka ke jalan Allah. Semasa tinggal di Kedah, beliau sering menyampaikan pengajaran agama di masjid-masjid, di surau-surau terutama di Kedah. Sebagai seorang guru yang tinggi ilmunya, pengajiannya mendapat sambutan hangat dari masyarakat setempat. Selain itu, ia juga diminta oleh Radio RTM Kedah, untuk

\footnotetext{
${ }^{13}$ Saifuddin; Dzikri Nirwana, dan Bashori. Peta Kajian Hadis Ulama Banjar hlm. 137-146. lihat juga Wardianysah. Biografi Singkat KH. M. Syukeri Unus Dan Sejarah Majlis Ta'lim Sabilal Anwar Al-Mubarak. Antasan Senor Ilir Martapura (Martapura: Sabilal Anwar. t.tp) hlm. 1-57.
} 
mengisi Ruang Kemusykilan Agama (Masalah-masalah Agama), yang disiarkan secara langsung sejak tahun 1994 M. hingga 2001 M.

Pada tahun 2001 M. beliau mendirikan pondok pesantren YASIN di Muara Teweh, Kalimantan Tengah Indonesia. Seterusnya pada tahun 2003 M. beliau mendirikan pondok pesantren YASIN kedua di Banjarbaru, Kalimantan Selatan Indonesia. Kemudian Ponpes yang ketiga, pada tahun 2009 M., membangun lagi Pondok pesantren di Balikpapan, Kalimantan Timur Indonesia. Justeru, sejak tahun 2001 M., beliau senantiasa pulang-pergi antara Malaysia dan Indonesia. Beliau juga pernah diberi amanah untuk memimpin Majelis Ulama Indonesia (MUI) Kabupaten Barito Utara, Kalimantan Tengah, periode 2004-2009 M.

Meskipun sibuk mengajar, juga menyempatkan mengarang dan menyusun kitab dalam pelbagai disiplin ilmu seperti:

- Terjemah Qashidah Burdah

- Sejarah Hidup Sayyid Abul Hasan al-Nadwi

- Empat Puluh Hadis Peristiwa Akhir Zaman (edisi Arab Melayu dan Latin)

- Sejarah Perkembangan Islam di India

- Empat Puluh Hadis Penawar Hati

- Terjemah Kitab Bidāyah al-Hidayah

- Terjemah Kitab Bustān al- 'A Arifin

- Kiamat Hampir Tiba

- Terjemah Kitab Yä Bunayya

- Bekal Akhirat

- Empat Puluh Hadis Akhlak Mulia

- Terjemahan Empat Puluh Hadis

- Sejarah Hidup Sayyid Muhammad Alwi al-Maliki dan Pemikirannya.

- Tahqīq kitab Sayr al-Sälikin

- Taḥqīq kitab Hidāyah al-Sālikīn

- Terjemah Kitab Ayyuhā al-Walad. ${ }^{14}$

\section{HADIS $A R B A^{\prime} \bar{I} N$ ULAMA BANJAR ABAD $20 \mathrm{M}$.}

Ulama Banjar dalam menuliskan hadis Arba'in tidak mengikut makna dari Arba'in tersebut, akan tetapi mereka menuliskan hadis Arba'in mengikut kepada tradisi ulamaulama sebelum mereka yang telah menuliskan hadis Arba'in. Hal ini terlihat daripada kitab hadis Arba'in yang mereka tulis tidak semua tepat berisi 40 hadis walaupun nama atau tajuknya hadis 40. Contohnya di tulis oleh Ahmad Fahmi Zamzam iaitu kitab 40 Hadis Peristiwa Akhir Zaman. Jika melihat maknanya berisi 40 hadis tepat,

${ }^{14}$ Ahmad Syahbuddin. 2012. Manhaj Al-Shaikh Al-Häjj Ahmad Fahmì Zamzam Al-Banjarì Al-Nadwi

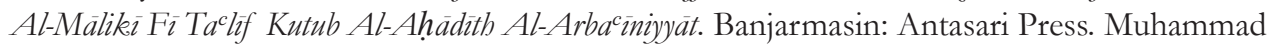
Hasan. Peta Perkembangan Kajian Hadis Al-Arbaìn Di Kalimantan Selatan. hlm.53-56. Saifuddin; Dzikri Nirwana, dan Bashori. Peta Kajian Hadis Ulama Banjar hlm. 137-146. Suhanim Abdullah. Pemikiran Tokoh Ulama Banjar Kedah (Batu Pahat: Awijaya Enterprise. 2014) hlm. 209-269. 
akan tetapi kitab yang beliau tulis berisikan 42 hadis. Hal ini menarik untuk diteliti, ternyata beliau menuliskan mengikut kebiasaan ulama dahulu.

Agar kita mudah melihat jumlah hadis dalam kitab mereka maka ada disebutkan pada senarai berikut.

- Kitab al-Tabyinn al-Rawi Sharh 'Alā Arba'in al-Nawawi, karya daripada Muhammad Kasyful Anwar berisikan 42 hadis.

- Kitab Hidāyah al-Zamān min Ahādīth Ākbir al-Zamān, karya daripada Anang Sya'rani Arif berisikan 40 hadis.

- Hadīth al-Arba'in fi al-'Ilm, karya daripada Muhammad Syukeri Unus berisikan 40 hadis.

- Kitab 40 Hadis Peristiwa Akhir Zaman, karya daripada Ahmad Fahmi Zamzam berisikan 42 hadis.

- Kitab 40 Hadis Penawar Hati, karya daripada Ahmad Fahmi Zamzam berisikan 42 hadis. $^{16}$

\section{Hadis Arba'īn Ditulis di Banjar}

Peranan ulama banjar dalam menuliskan hadis perlu di apresiasi dihargai dan disanjung. sebab mereka menuliskan hadis maka kita dapat merasakan dan menjumpai hadis Nabi SAW. Seandainya mereka tidak menuliskan tentu tidak akan sampai kepada kita sekarang ini. Usaha mereka dalam menuliskan hadis $A r b a^{c} i n$ berlaku di dua tempat yakni di Banjar dan Malaysia.

\section{Kitab al-Tabyīn al-Rawī Sharh' Alā Arba'̄in al-Nawawī}

Kitab al-Tabyin al-Rawi Sharh 'Alä Arba'in al-Nawawi merupakan karya Muhammad Kasyful Anwar. Kitab ini memuat 42 hadis yang berisi sharh kepada hadis Arbain karya imam al-Nawawi. ${ }^{17}$ Selain itu, kitab ini sering dan diguna pakai oleh pelajar di Pondok-pondok dan juga di masyarakat pada umumnya kerana kitab ini merupakan kitab yang lebih senang untuk dipelajari dan difahami masyarakat awam untuk mengamalkan hadis Nabi SAW. Kitab ini ditulis menggunakan tulisan jawi sehingga memudahkan pelajar dan masyarakat untuk memahami. Bahasa yang digunakan beliau dalam memberikan sharh sangat baik dan tepat kepada keadaan masyarakat tempatan.

Muhammad Kasyful Anwar memiliki karya di dalam bidang hadis Arbain yang di beri nama Kitab al-Tabyīn al-Rawī bermakna penjelasan yang sempurna. Penulisan kitab al-Tabyīn al-Rawī disebutkan dalam mukadimah kitab bahawa penulisan bermula pada hari bulan Kamis pagi, 4 Ramadhan 1355 H. atau bertepatan dengan

${ }^{15}$ Muhammad Syukeri Unus. Hadith Al-Arbacin Fi Al-c Ilm. (Martapura: Darussyakirin, t.th) hlm. $1-49$.

${ }^{16}$ Ahmad Fahmi Zamzam. Edisi Istimewa 40 Hadis Peristiwa Akhir Zaman Serta Tiga Kitab 40 Hadis Dan Huraiannya Merangkumi Ilmu Dan Ulama, Akblak Mulia Dan Penawar Hati (PetalingJaya: Galeri Ilmu Sdn. Bhd. 2013) hlm.129. Ahmad Fahmi Zamzam. 40 Hadis Peristiwa Akbir Zaman. (Derang, Kedah: Khazanah Banjariah. 2015) hlm. 1-10. Ahmad Fahmi Zamzam. Empat Puluh Hadis Penawar Hati. (Derang, Kedah: Khazanah Banjariah. 2015) hlm. 1-5

${ }^{17}$ Muhammad Kasyful Anwar. Al-Tabyin Al-Rawi Sharh c Alä Arbacin Al-Nawawi. Penyt Munawar Ahmad Ghazali (Martapura: Putra Sahara Ofset. 2006) hlm. 1-157. 
18 November 1936 M. di Martapura. Penulisan kitab ini diselesaikan pada hari bulan Ahad pagi, 9 Zulhijah 1355 H bertepatan 21 Februari 1937 M.

Penyusunan kitab al-Tabyin al-Rawi Sharh 'Alä Arba'in al-Nawawi dalam penyusunannya disusun sesuai dengan hadis-hadis Arbain Imam al-Nawawī, berisi 42 hadis. Kitab ini ditulis dalam dua versi iaitu pertama, versi yang ditulis Shaikh Muhammad Syukeri Unus yang diterbitkan Dār al-Syākirīn, kitab ini tanpa tahun terbit, versi kedua yang ditulis oleh Guru Munawwar bin Ahmad Ghazālī, yang merupakan keturunan Shaikh Muhammad Kasyful Anwar dan dicetek oleh Putera Sahara Ofset. ${ }^{18}$

Kitab al-Tabyin al-Rawi Sharh 'Alä Arba'in al-Nawawi yang dicetak Putra Sahara Ofset Martapura Kalimantan Selatan, merupakan cetakan yang penulisan naskahnya telah disempurnakan Guru Munawwar pada hari bulan 23 Ramadhan $1427 \mathrm{H}$. bertepatan 16 Oktober 2006 M. Kitab ini ditulis dalam bahasa menggunakan tulisan jawi dan berukuran stander buku pada umumnya, memuat 157 muka surat. ${ }^{19}$

\section{Kitab Hidāyah al-Zamān Min Ahāāīth Ākhir al-Zamān.}

Kitab Hidāyah al-Zamān Min Ahääith Ākhir al-Zamān merupakan karya daripada Muhammad Anang Syacrani Arif. Kitab ini termasuk kitab hadis Arbain kerana memuat hadis sebanyak 40 hadis. Mengikut kepada tajuk yang beliau beri iaitu Hidāyah al-Zamān min Ahādīth Ākhir al-Zamān kitab ini merupakan kumpulan hadis yang memuat sejumlah hadis tentang peristiwa atau kejadian yang akan terjadi pada akhir zaman. Kitab ini merupakan kajian hadis dalam bidang ilmu riwāyah hadis, atau yang juga diistilahkan ilmu periwayatan hadis.

Kitab Hidāyah al-Zamān min Ahādīth Ākhir al-Zamān merupakan kitab yang tidak asing di kalangan pelajar pondok Darussalam Martapura kerana biasanya diguna pakai kalangan sendiri (kalangan pesantren Darussalam Martapura) dan masyarakat tempatan. Kitab ini dicetak dan diterbitkan oleh Pondok Pesantren Darussalam Martapura, Kalimantan Selatan Indonesia, tanpa disebutkan tahun terbit. Kitab ini berisi 28 muka surat yang ditulis menggunakan bahasa Arab. Selain itu kitab ini hanya dapat didapatkan pada saat haul Muhammad Anang Sya ${ }^{c}$ rani Arif. Isi kitab ini ditulis kembali oleh Abu Ahmad Jamaluddin bin Muhammad Arif di Martapura pada bulan Augustus 1999 M.

Pada dasarnya, hadis-hadis ini merupakan kejadian di akhir zaman yang Nabi Muhammad SAW gambarkan keadaan huru-hara serta merupakan kumpulan hadis keadaaan umat Nabi Muhammad SAW di akhir-akhir zaman nanti. Beliau berusaha menuliskan hadis ini sebagai peringatan bagi diri beliau sendiri mahupun seluruh umat Islam. Dalam hadis itu beliau cuba gambarkan dahsyatnya cabaran di akhir zaman. ${ }^{20}$

\footnotetext{
${ }^{18}$ Saifuddin; Dzikri Nirwana, dan Bashori. Peta Kajian Hadis Ulama Banjar hlm. 124.

${ }^{19}$ Muhammad Hasan Said Iderus, dkk. al-Tabyin al-Rawi Sharḥ Arbacin al-Nawawi Kitab Sharh Hadis Pertama di Banjar "KalimantanSelatan".hlm.150.

${ }^{20}$ Anang Syacrani Arif. Hidāyah Al-Zamān Min Ahäà̃th Ākhir Al-Zamān. hlm. 1-28. Muhammad Hasan. Peta Perkembangan Kajian Hadis Al-Arbacin Di Kalimantan Selatan. hlm. 71-74.
} 


\section{Hadis Arba'īn fì al-' $\mathbf{I l m}$}

Kitab hadis $A r b a^{c}$ in fì al- ${ }^{-} I l m$ merupakan karya daripada Muhammad Syukeri Unus dalam bidang hadis Arbain. Kitab ini telah diberikan Tạqiq murid beliau Ahmad Fahmi Zamzam sehingga menjadikan kitab ini didapati dalam beberapa bahasa seperti Arab, Indonesia, Malaysia dan versi Tah̆qiq. Kitab ini dicetak dan guna pakai di Negara Malaysia. Ulama tempatan bisa menjadikan kitab ini sebagai kitab pegangan untuk pelajar dalam menuntut ilmu.

Kitab versi bahasa Arab di cetak oleh Majlis Taclim Sabilal Anwar Al-Mubarak di bawah asuhan KH. Muhammad Syukeri Unus. Kitab ini berukuran stander buku, berisi 48 halaman, dengan memuat bagian: Foto KH. Muhammad Syukeri Unus, berserta Ijazah kitab tersebut. ${ }^{21}$

\section{Hadis Arba'īn Ditulis Di Malaysia}

Peranan ulama Banjar abad 20 M. dalam menuliskan hadis Arbain berlaku tidak hanya di Banjar melainkan juga didapati penulisan hadis Arbain di Malaysia. Walaupun ditulis di Malaysia kitab ini diguna pakai sama ada di Banjar Kalimantan Selatan, Muara Teweh Kalimantan Tengah, Balikpapan Kalimantan Timur, mahupun di Malaysia. Hal ini menjadi menarik untuk diteliti kerana peranan mereka dalam menyumbangkan karya di bidang hadis tidak hanya di Banjar melainkan juga di Malaysia. Kitab yang mereka tuliskan diguna pakai di pengajian di surau-surah di Malaysia di pondok-pondok.

\section{Kitab 40 Hadis Peristiwa Akhir Zaman,}

Kitab 40 Hadis Peristiwa Akhir Zaman ini merupakan karya kepada Ahmad Fahmi Zamzam berisi sejumlah hadis tentang keadaan dan peristiwa yang akan terjadi menjelang hari kiamat. Kitab ini berisi 42 hadis Nabi SAW. Kitab ini dicetak dalam dua versi terbitan iaitu: TB Darussalam Yasin dan versi terbitan Galeri Ilmu Malaysia Sdn Bhd. Versi yang dicetak dalam TB Darussalam Yasin di cetak dengan ukuran stander buku, dan berisi 106 muka surat dan memuat bahagian-bahagian: Judul, keterangan penerbitan dan hak cipta, Selawat kepada Nabi Muhammad SAW, Kandungan (Daftar Isi), Mukadimah penulis (Ahmad Fahmi Zamzam) berisi motivasi penulisan yang disertai hadis-hadis yang relevan. Deskripsi hadis yang memuat hadis sesuai tema, terjemahan ke bahasa Indonesia berserta keterangan hadis (penjelasan singkat oleh KH. Ahmad Fahmi Zamzam) Intisari kitab berisi nasihat-nasihat. dan Huraian takhrij untuk semua hadis yang ada dalam kitab. Kitab yang ditulis beliau ini senang untuk difahami semua kalangan sehingga membuat pembacanya tidak merasa jenuh ketika membaca.

Sedangkan versi lain 40 Hadis Peristiwa Akhir Zaman cetakan Galeri Ilmu Galeri Ilmu Sdn. Bhd, fragmen kitab 40 Hadis Peristiwa Akhir Zaman ini berada pada bahagian keempat, berjumlah 117 muka surat (bermula pada muka surat 417 hingga 534) versi ini ditulis menggunakan bahasa Melayu untuk teks terjemah hadis dan penjelasan ringkasnya, dengan tetap menyertakan teks hadis berbahasa Arab. Kitab yang berukuran stander buku ini, memuat beberapa bagian; Mukadimah penulis

\footnotetext{
${ }^{21}$ Muhammad Syukeri Unus. Hadith Al-Arbacin Fï Al-cllm. (Martapura: Darussyakirin, t.th) hlm $1-49$.
} 
tentang latar belakang, motivasi, dan harapan dalam menyusun kitab, dengan mengutip beberapa hadis yang relevan. Deskripsi 42 hadis yang relevan dengan tema kitab, berikut terjemah dan penjelasannya secara ringkas, yang di himpun dari berbagai kitab hadis. Penutup dari penulis, berisi kesimpulan 10 intisari dakwah dari 40-an hadis yang telah diuraikan. Doa agar dikuatkan iman dan dipelihara dari kekufuran, kefasiqan dan kemaksiatan. Huraian takhrij untuk semua hadis yang ada dalam kitab. ${ }^{22}$

\section{Kitab 40 Hadis Penawar Hati}

Kitab hadis Arbain selanjutnya yang di tulis di Malaysia adalah 40 Hadis Penawar Hati. kitab ini merupakan karya kepada Ahmad Fahmi Zamzam al-Banjari. Dalam 40 Hadis Penawar Hati ini membahas tentang keutamaan dan pentingnya fungsi hati bagi manusia, serta cara-cara yang harus dilakukan seseorang untuk menjaga hati agar terhindar dari kekotoran dan dosa. melalui hadis-hadis pilihan yang berjumlah 42 hadis.

Versi ini merupakan edisi istimewa yang merupakan terbitan Galeri Ilmu Sdn. Bhd. fragmen kitab 40 Hadis Penawar Hati ini berada pada bagian kedua, berjumlah 148 muka surat (bermula pada muka surat 129 hingga 277), ditulis dalam bahasa Melayu (Malaysia) untuk teks terjemah hadis dan penjelasan ringkasnya, dengan tetap menyertakan teks hadis berbahasa Arab. Kitab yang berukuran stander buku ini, memuat beberapa bagian, iaitu: Mukadimah penulis (Ahmad Fahmi Zamzam), kemudian tentang latar belakang, motivasi, dan harapan dalam menyusun kitab, dengan mengutip beberapa hadis dan ayat al-Quran yang relevan, selanjutnya isi 42 hadis yang relevan dengan tema kitab, berikut terjemah dan penjelasannya secara ringkas, yang di himpun daripada pelbagai kitab hadis. Kemudian terakhir Penutup dari Ahmad Fahmi Zamzam, di penutup ini berisi harapan untuk beliau agar umat Muslim menyedari pentingnya akhirat sebagai kehidupan yang abadi.

Selain itu harapan ditulisnya kitab itu untuk melakukan persiapan di dunia guna menghadapi kehidupan akhirat tersebut dengan amal-amal ibadah. sama ada bagi diri sendiri mahupun keluarga. contoh kehidupan dan keimanan Rasulullah saw. dan para sahabatnya, dan ajakan untuk bertaubat dan selalu berharap kepada Allah. Kitab Versi ini memuat doa agar di kurniakan ketenangan dan kebersihan hati kaum Muslimin. selain itu juga kitab ini memuat Huraian takhrij untuk semua hadis yang ada dalam kitab.

Sedangkan versi terbitan lain sebenarnya tidak jauh berbeza. agar kiranya kita dapat melihat versi lain. Versi ini memuat 114 muka surat, dan ditulis menggunakan bahasa Arab untuk hadis dan terjemah serta keterangan yang memuat penjelasan Ahmad Fahmi Zamzam menggunakan bahasa Indonesia. Kitab ini menggunakan bahasa yang mudah difahami semua golongan. Kitab ini berukuran stander buku dengan memuat beberapa bahagian, iaitu: Judul kitab berserta hak cipta, selawat kepada Nabi Muhammad SAW., kandungan kitab, Mukadimah oleh Ahmad Fahmi Zamzam, serta hal yang menjadi latar belakang sama ada motivasi mahupun harapan beliau ketika menyusun kitab ini. Semua bahagian ini di isi beliau dengan mengutip

\footnotetext{
${ }^{22}$ Versi ini merupakan cetakan seluruh hadis Arbain Ahmad Fahmi Zamzam. lihat Ahmad Fahmi Zamzam. Edisi Istimewa 40 Hadis Peristiwa Akhir Zaman Serta Tiga Kitab 40 Hadis Dan Huraiannya Merangkumi Ilmu Dan Ulama, Akblak. Mulia Dan Penawar Hati hlm. 129-268. lihat Ahmad Fahmi Zamzam. 40 Hadis Peristiwa Akbir Zaman. hlm. 1-127.
} 
beberapa hadis dan ayat al-Quran yang relevan. Kemudian kitab ini berisikan 42 hadis yang beliau pilih dengan tema kitab, disertai terjemah dan penjelasannya secara ringkas menggunakan bahasa Indonesia. Di akhir bahagian ini diisi penutup dari oleh Ahmad Fahmi Zamzam, pada bahagian ini beliau menuliskan harapan dan keinginan beliau agar kaum Muslimin dapat menyedari pentingnya akhirat dan mempersiapkan dari sekarang dengan cara mengisi hidup dengan beramal ibadah. Bahagian berikutnya dituliskan Huraian takhrij kepada semua hadis yang ada di dalam kitab. ${ }^{23}$

\section{Kesan Hadis Arba'īn Ulama Banjar Abad 20 M.}

Melihat kerana hadis Arbain yang ditulis ulama Banjar memiliki kesan baik kepada masyarakat, maka kitab-kitab yang di tulis oleh ulama banjar di Abad $20 \mathrm{M}$ mendapatkan tempat di hati para kaum Muslimin sama ada di Indonesia Mahupun di Malaysia. Justeru ini menjadi menari untuk dikaji dan diteliti lebih mendalam oleh Sarjana Muslim guna memartabatkan kedudukan ulama Nusantara.

\section{Digunakan di Kalangan Masyarakat Awam}

Kitab hadis Arbain yang ditulis oleh ulama banjar menjadi senang difahami masyarakat kerana hampir semua kitab hadis Arbain yang ditulis ulama Banjar sesuai dengan keadaan masyarakat. Hal ini dapat kita contohkan kepada kitab al-Tabyin al-Rawi ${ }^{24}$ yang disusun dan ditulis oleh Muhammad Kasyful Anwar. Kitab ini beliau tulis menggunakan tulisan jawi. Pada masa itu tulisan jawi dan menggunakan bahasa tempatan sehingga masyarakat menjadi merasa dekat dan senan memahami hadis Nabi SAW.

Disebutkan oleh Guru Ini Munawwar dalam pengantar kitab Muhammad Kasyful Anwar bahawa secara metode, sharh hadis yang ditulis oleh Muhammad Kasyful Anwar ini bersifat umum akan tetapi dalam penjelasannya Muhammad Kasyful Anwar memberikan makna hadis yang susah difahami dengan bahasa yang mudah dimengerti semua kalangan kaum Muslim. Ungkapan-ungkapan yang digunakan sangat mudah dan jelas, di dalam penjelasannya biasanya beliau memuat penjelasan menggunakan beberapa kitab yang muktabar, sehingga memudahkan untuk dibaca dan difahami sesuai sama ada kandungan mahupun istilahnya. Masyarakat awam biasa mempelajari daripada pengajian di surau-surau.

\section{Hadis Arba'īn Sebagai Motivasi Beribadah}

Kitab hadis Arbain berikutnya didapati seperti kitab yang ditulis oleh Muhammad Syukeri Unus yang bertajuk Hadis Arbain fï Ilm ini ada kemungkinan kerana beliau mengajar di Pondok Pesantren untuk memotivasikan pelajar-pelajar beliau lebih mencintai ilmu. Selain itu beliau juga melihat perlunya para pelajar di pondok untuk memahami kelebihan dan keutamaan untuk menuntut ilmu. Kitab ini di jadikan

\footnotetext{
${ }^{23}$ Muhammad Hasan. Peta Perkembangan Kajian Hadis Al-Arbacin Di Kalimantan Selatan. hlm. 79-87.

${ }^{24}$ Kitab ini merupakan kitab yang diharapkan beliau dapat memudahkan masyarakatan memahami hadis Nabi SAW. yang disusun oleh imam al-Nawawī. Muhammad Kasyful Anwar. Al-Tabyīn Al-Rawi Sharh c Alä Arbacin Al-Nawawi. Penyt Munawar Ahmad Ghazali (Martapura: Putra Sahara Ofset. 2006) hlm. 1-5.
} 
pelajar sebagai motivasi untuk selalu menuntut ilmu. Selain itu kitab yang di tulis ulama Banjar menjadi motivasi untuk lebih mendekatkan diri kepada Allah serta mengimani hari Kiamat.

\section{Digunakan di Kalangan Pondok}

Pondok merupakan tempat yang tepat untuk menuntut ilmu. Pondok banyak berjasa kepada bangsa dan Tanah Air kerana banyak lulusan pondok menjadi orang yang berperanan kepada penyebaran Islam dan pengajaran kepada umat Islam. Pondok menjadi pusat keilmuan Islam. Kitab hadis Arbain ini juga digunakan di Pondokpondok sama ada di Banjar Mahupun di Malaysia. Hal ini dapat dicontohkan kitab hadis Arbain yang ditulis oleh Ahmad Fahmi Zamzam. Kitab yang beliau susun dan tulis menjadi kitab penting bagai pelajar pondok yang beliau didik.

\section{Digunakan para Ustaz untung Mengajar di Surau-surau}

Ustaz memiliki peranan kepada perkembangan dan pengajaran Islam. kerana ustaz memainkan peranan dakwah Islam, Disebabkan banyaknya para ustaz lulusan pondok yang mengajar di surau-surau tidak sedikit ulama yang belajar kepada ulama Banjar mengajar menggunakan kitab yang dipelajari di pondok. Misalnya kitab pelajar pondok Darussalam Martapura yang telah lulus dan berpengaruh di kampungnya biasa mengajar hadis Arbain yang telah dipelajari dan digunakan di pondok. ${ }^{25}$

\section{Simpulan}

Ulama merupakan pewaris para Nabi sehingga para ulama memiliki peranan penting dalam menyampaikan dan mengajak kepada kebaikan. Ulama Banjar memiliki peranan sangat penting dari masa ke semasa sama ada dalam biang akhlak, tasawuf, al-Quran mahupun hadis. Tidak sedikit ulama Banjar di Abad $20 \mathrm{M}$ memiliki peranan penting terhadap penulisan hadis Arbain di Banjar dan Malaysia. Kitab-kitab yang mereka tulis telah beberapa kali cetak dan diguna pakai di pondok pesantren dan pengajian di surau-surau sama ada di Indonesia mahupun Malaysia.

Motivasi yang mendorong mereka untuk menuliskan hadis lebih kepada dakwah untuk mengajak umat Islam lebih dekat dan bermotivasi melakukan dakwah sama ada kepada diri sendiri mahupun mengajak keluarga. Masyarakat Banjar, khususnya yang berdomisil di Kalimantan Selatan, dan beragama Islam memiliki hubungan yang sangat erat, bahkan tidak dapat dilepaskan dari ke seharian masyarakat. Hal ini terlihat dari berbagai adat dan budaya yang banyak berwarna Islam. Terlebih lagi Kalimantan Selatan banyak memiliki ulama-ulama besar yang menulis berbagai kitab keislaman dan termasuk halnya dalam bidang hadis terutama dalam hadis Arbain.

Perhatian ulama Banjar di abad $20 \mathrm{M}$ terhadap penulisan hadis terutama hadis Arba'in memberikan kesan baik kepada masyarakat Muslim. Hal yang menarik perhatian bahawa kerana pengaruh baik mereka maka kitab yang mereka susun dan

${ }^{25}$ Ulama memainkan peranan penting daro aspek agama sehingga melakukan penyebaran dan pengenalan Islam salah satunya dengan melakukan kuliah di surau. Shukri Ahmad. Pengaruh Pemikiran Ulama Di Semenanjung Malaysia Akbir Abad Ke-20. hlm. 125-140. lihat Suhanim Abdullah. Pemikiran Tokoh Ulama Banjar Kedah hlm. 21-110 
tulis sesuai untuk diterapkan dan diguna pakai umat Islam dari masa ke semasa. Pada awal abad ke-20 M. Muhammad Kasyful Anwar memberikan sharh terhadap kitab Arba'in imam al-Nawawī yang kemudian diikuti ulama berikutnya pada pertengahan abad ke-20 M. muncul kumpulan 40 hadis yang ditulis oleh Muhammad Anang Sya ${ }^{c}$ rani Arif dan seterusnya.

Keberadaan ulama Banjar di abad $20 \mathrm{M}$, yang telah berusaha dalam mengumpulkan dan menyusun hadis Arbain merupakan barakah bagi kaum Muslim pada umumnya sama ada di Indonesia mahupun di Malaysia, Karya ulama Banjar mereka hingga saat ini diguna pakai dan menjadi rujukan pelajar Muslim. Mereka memiliki jasa yang sangat besar dalam menanamkan nilai-nilai keislaman.

\section{DAFTAR PUSTAKA}

Ahdi Makmur. 2010. Peranan ulama dalam masayarakat banjar. Universiti Utara Malaysia.

Ahmad Fahmi Zamzam. 2013. Edisi Istimewa 40 Hadis Peristiwa Akbir Zaman Serta Tiga Kitab 40 Hadis Dan Huraiannya Merangkumi Ilmu dan Ulama, Akblak Mulia dan Penawar Hati. PetalingJaya: Galeri Ilmu Sdn. Bhd.

. 2015a. 40 Hadis Peristiwa Akbir Zaman. Rumi Stand. Derang, Kedah: Khazanah Banjariah.

- 2015b. Empat Pulub Hadis Penawar Hati. Derang, Kedah: Khazanah Banjariah.

Ahmad Sunawari Long. 2015. Metodologo Penyelidikan Pengajian Islam (Bangi: Penerbit Universisti Kebangsaan Malaysia.

Ahmad Syahbuddin. 2012. Manhaj Al-Shaikh Al-Häjj Ahmad Fahmì Zamzam Al-Banjari Al-Nadwi Al-Mälikè Fì Taclîf Kutub Al-Ahädìth Al-Arbaciniyyät. Banjarmasin: Antasari Press.

Anang Sya'rani Arif. 1999. Hidāyah Al-Zamān Min Ahādìth Ākbir Al-Zamān. Pondok Pesantren Darussalam Martapura.

Badri Khaeruman, 2010. Ulumul al-Hadis. Bandung: Pustaka Setia.

Bayani Dahlan, 2009. Ulama Banjar Dan Karya-Karyanya. Banjarmasin: Antasari Press. Mazlan Ibrahim, Haziah Hussain, \& Latifah Abdul Majid. 2012. Warisan Hadisth Ulama Nusantara. Bangi: Universiti Kebangsaan Malaysia.

Muhammad Hasan. 2014. Peta Perkembangan Kajian Hadis Al-Arba'in Di Kalimantan Selatan. Banjarmasin: Antasari Press.

Muhammad Hasan Said Iderus dkk. 2016. Al-Tabyin al-Rawi Sharh Arba'in al-Nawawì Kitab Sharh Hadis Pertama di Banjar "Kalimantan Selatan". Proseding Jejak. Warisan Ilmu Islam .

Muhammad Kasyful Anwar. 2006. Al-Tabyin Al-Rawì Sharh 'Alä Arba'in Al-Nawawī. Munawar Ahmad Ghazali (pnyt.). Putra Sahara Ofset.

Muhammad Syukeri Unus. t.th. Hadith Al-Arba'in Fi Al-'Ilm. Martapura: Darussyakirin. Munawwar bin Ghazali. t.th. Nur Al-Abṣär Fī Zikr Nubzah Min Manaqib Al-Shaikh Muhammad Kasyful Anwar. Martapura: Putra Sahara Ofset. 
Muhammad Hasan Said Iderus, dkk Peranan Ulama Banjar Abad Ke-20 163

Rahmadi, \& Husaini Abbas. 2012. Islam Banjar Genelogi Dan Refrensi Intelektual Dalam Lintasan Sejarah. Banjarmasin: Antasari Press.

Saifuddin; Dzikri Nirwana;, \& Bashori. 2014. Peta Kajian Hadis Ulama Banjar. Banjarmasin: IAIN Antasari.

Shukri Ahmad. 2014. Pengaruh Pemikiran Ulama Di Semenanjung Malaysia Akbir Abad Ke-20. 2nd ed. Kedah: UUM Press.

Suhanim Abdullah. 2014. Pemikiran Tokoh Ulama Banjar Kedah. Batu Pahat: Awijaya Enterprise.

Tim Pustaka Basma. 2014. Tiga Permata Ulama Dari Banjar. Malang: Pustaka Basma.

Wardianysah. t.th. Biografi Singkat KH. M. Syukeri Unus Dan Sejarah Majlis Ta'lim Sabilal Anwar Al-Mubarak. Antasan Senor Ilir Martapura. Martapura: Sabilal Anwar. 